\title{
Cerebral Ventriculomegaly in Myotonic Dystrophy Type 1: Normal Pressure Hydrocephalus-like Appearances on Magnetic Resonance Imaging
}

Saya lida

Hirosaki University

Hiroko Seino

Hirosaki University

Fumiko Nagahata

Aomori Hospital

Soichiro Tatsuo

Hirosaki University

Sho Maruyama

Hirosaki University

Seiko Kon

Aomori hospital

Hiroto Takada

Aomori hospital

Masashi Matsuzaka

Hirosaki university

Koichiro Sugimoto

University of Occupational and Environmental Health

Shingo Kakeda ( $\sim$ kakeda@med.uoeh-u.ac.jp )

Hirosaki Daigaku Igakubu Daigakuin Igaku Kenkyuka https://orcid.org/0000-0002-0521-9728

\section{Research article}

Keywords: myotonic dystrophy, ventriculomegaly, Evans Index, normal pressure hydrocephalus, disproportionately enlarged subarachnoid-space hydrocephalus, MRI

Posted Date: January 19th, 2021

DOI: https://doi.org/10.21203/rs.3.rs-147896/v1

License: (a) (i) This work is licensed under a Creative Commons Attribution 4.0 International License.

Read Full License 


\section{Abstract}

Background: Cerebral ventriculomegaly is an abnormal feature characteristic of myotonic dystrophy type 1 (DM1). This retrospective study investigated the morphologic changes accompanied by ventriculomegaly in DM1 on brain MRI.

Methods: One hundred and twelve adult patients with DM1 and 50 sex- and age-matched controls were assessed. The imaging characteristics for evaluations included the z-Evans Index (ventriculomegaly), callosal angle (CA), enlarged perivascular spaces in the centrum semiovale (CS-EPVS), temporo-polar white matter lesion (WML) on 3D fluid-attenuated inversion recovery (FLAIR), disproportionately enlarged subarachnoid-space hydrocephalus (DESH), and pathological brain atrophy. The "z-Evans Index" was defined as the maximum z-axial length of the frontal horns to the maximum cranial z-axial length. To determine the imaging characteristics and genetic information (CTG repeat numbers) that were associated with the z-Evans Index, we used multivariate logistic regression analyses.

Results: The $z$-Evans Index was significantly larger in the patients than in the controls $(0.30 \pm 0.05$ vs. 0.24 $\pm 0.02 ; p<0.01)$. The multivariate logistic regression analyses showed that the $z$-Evans Index was independently associated with the patient age $(p<0.05), C A(p<0.01)$, Sylvian fissure dilation $(p<0.01)$, and pathological brain atrophy $(p<0.01)$ but not with CTG repeat numbers, CS-EPVS, or temporo-polar WML. Of the 34 patients older than 49 years, 7 (20.6\%) were considered to have DESH.

Conclusions: Our MRI study revealed a normal pressure hydrocephalus (NPH)-like appearance as a morphologic finding accompanied by ventriculomegaly in DM1 that tends to occur in elderly patients.

\section{Background}

Myotonic dystrophy type 1 (DM1) is the most common disease that can cause muscle weakness and atrophy among adults[1]. The genetic defect underlying DM1 is multiple CTG repeats in the $3^{\prime}$ untranslated region of a gene (DM1) on the long arm of the chromosome: the analysis of the CTG repeat on chromosome 19q13[2]. Neuropathological, neuroimaging, and neurophysiological studies have demonstrated a variety of abnormalities of the central nervous system in DM1 patients[3-5]. Magnetic resonance imaging (MRI) has been widely used to evaluate DM1. Previous MRI studies with DM1 demonstrated ventriculomegaly and "unusual" white matter lesions (WMLs) in the anterior or medial portions of the temporal lobes (temporo-polar WMLs)[6]. Enlarged perivascular spaces (EPVS) on MRI were also seen in the centrum semiovale (CS) and basal ganglia in DM1[7].

Normal pressure hydrocephalus (NPH) is a disease affecting the elderly population, with symptoms of balance and gait disturbances, dementia, and urinary incontinence. ${ }^{1,2}$ The clinical evaluation of patients with NPH still often relies on morphologic findings. The study of NPH on Neurologic Improvement (SINPHONI) described important MRI features for the NPH diagnosis ${ }^{[8]}$ as high-convexity tightness and an enlarged Sylvian fissure with ventriculomegaly, designated as "disproportionately enlarged subarachnoid-space hydrocephalus (DESH)." The Evans Index has also been the most popular index of 
ventriculomegaly. Through our work, we have noticed that the MRI features specified in NPH (NPH-like appearance $=\mathrm{DESH}$ ) are frequently seen in DM1 patients.

Ventriculomegaly is a characteristic MRI finding in DM1[9]. However, to our knowledge, no previous studies have evaluated the morphologic MRI changes accompanied by ventriculomegaly in DM1. Furthermore, no previous studies have mentioned "NPH-like appearances" in DM1 patients, although Wang et al. demonstrated the coexistence of DM1 and NPH, as five patients were available for case reviews[10].

The present study therefore investigated the frequency of an NPH-like appearance in DM1 patients. We also determined whether or not an NPH-like appearance was associated with the clinical characteristics and previously described typical DM1 features on brain MRI.

\section{Methods}

\section{Subjects}

Our ethics review committees approved this retrospective study, and the need to obtain informed consent from the patients was waived.

We routinely perform screening brain MRI studies to assess DM1 patients. One radiologist (** with 4 years of neuroradiology experience) reviewed a clinical database between April 2018 and May 2020 and selected adult 112 patients who had been diagnosed with DM1 based on a clinical examination, electromyography, and underlying genetic defects (the analysis of the CTG repeat on chromosome 19q13 by standard techniques[11]). All 112 patients had undergone brain MRI. No patients were excluded based on the exclusion criteria, including patients with a history of other neurological diseases and/or unsatisfactory images due to artifacts (Table 1). 
Table 1

Clinical and imaging characteristics of DM1 and controls.

\begin{tabular}{|c|c|c|c|c|}
\hline & & DM1 $(n=112)$ & $\begin{array}{l}\text { Controls }(n= \\
50)\end{array}$ & $\begin{array}{l}p \\
\text { value }\end{array}$ \\
\hline \multirow{3}{*}{$\begin{array}{l}\text { Clinical } \\
\text { characteristics }\end{array}$} & \multirow[t]{2}{*}{ Age, mean (IQR) } & 44.3 & 45.7 & \multirow[t]{2}{*}{0.49} \\
\hline & & $(36-53)$ & $(38-53)$ & \\
\hline & sex, female (\%) & $48(43)$ & $26(52)$ & 0.31 \\
\hline DM1 related factors & $\begin{array}{l}\text { CTG repeat numbers, mean } \\
\text { (IQR) }\end{array}$ & $\begin{array}{l}950(600- \\
1366)\end{array}$ & NA & NA \\
\hline \multirow{9}{*}{$\begin{array}{l}\text { Imaging } \\
\text { characteristics }\end{array}$} & \multirow[t]{2}{*}{ Z-El, mean (IQR) } & 0.29 & 0.24 & \multirow[t]{2}{*}{$<.01$} \\
\hline & & $(0.27-0.32)$ & $(0.23-0.26)$ & \\
\hline & \multirow[t]{2}{*}{ callosal angle, mean (IQR) } & 123 & 123 & \multirow[t]{2}{*}{0.83} \\
\hline & & $(115-129)$ & $(112-127)$ & \\
\hline & Sylvian fissure dilation, $\mathrm{n}(\%)$ & $61(54)$ & $2(4)$ & $<.01$ \\
\hline & $\begin{array}{l}\text { high-convexity tightness, } n \\
(\%)\end{array}$ & $9(8)$ & $0(0)$ & 0.06 \\
\hline & CS-EPVS, n (\%) & $35(31)$ & $9(18)$ & 0.09 \\
\hline & temporo-polar WMH, n (\%) & $82(73)$ & $0(0)$ & $<.01$ \\
\hline & $\begin{array}{l}\text { pathological brain atrophy, } \mathrm{n} \\
\text { (\%) }\end{array}$ & $46(41)$ & $1(2)$ & $<.01$ \\
\hline $\begin{array}{l}\text { Abbreviations: DM1 = } \\
\text { Z-Evans Index; CS-EP } \\
\text { temporo-polar white r }\end{array}$ & $\begin{array}{l}\text { yotonic dystrophy type } 1 ; \mathrm{IQR}= \\
=\text { enlarged perivascular space } \\
\text { tter lesion. }\end{array}$ & $\begin{array}{l}\text { erquartile range } \\
\text { centrum semio }\end{array}$ & $\begin{array}{l}A=\text { not applica } \\
\text { le; temporo-pol }\end{array}$ & $\begin{array}{l}\mathrm{Z}-\mathrm{El}_{1}= \\
\mathrm{VML}=\end{array}$ \\
\hline
\end{tabular}

We selected 50 age- and sex-matched controls from the same sample population who had no history of neurological or psychiatric diseases and who had undergone MRI. The indications for their examinations included screening, headaches, or benign positional vertigo. By reviewing the neuroradiologists (** with 20 years of experience in neuroradiology), the conventional MRI results were normal in all controls.

\section{Image acquisition}

All studies were performed using a 1.5-T scanner (Magnetom Symphony, Syngo Version VE11C; Siemens Medical Systems, Erlangen, Germany) equipped with high-performance gradients (maximal gradient strength, $40 \mathrm{~m} \mathrm{Tm}^{-1}$ and maximal slew rate, $200 \mathrm{~m} \mathrm{Tm}^{-1} / \mathrm{ms}$ ) using a standard head coil. All patients and controls underwent brain MRI according to our standard protocol, including axial T2-weighted imaging (T2WI), two-dimensional (2D) coronal fluid-attenuated inversion recovery (FLAIR) imaging, and threedimensional (2D) sagittal FLAIR. For 3D FLAIR (3D fast spoiled gradient-echo imaging), we used three 
cross-section images (coronal, axial, and sagittal) reconstructed from the images obtained on the sagittal plane. The imaging parameters (repetition time $\mathrm{ms} / \mathrm{echo}$ time $\mathrm{ms} /$ inversion time/NEX/echo train length/matrix/field of view/imaging time) were 4,000/85/NA/2/9/226 $\times 384 / 23 \mathrm{~cm} / 2 \mathrm{~min}$ and $12 \mathrm{~s}$ for 2D T2WI and 9,000/108/2,500/1/14/208 $\times 320 / 22 \mathrm{~cm} / 3 \mathrm{~min}$ and $18 \mathrm{~s}$ for 2D FLAIR imaging, respectively. The 2D T2WI and 2D FLAIR images were acquired at a section thickness of $5 \mathrm{~mm}$, an intersection gap of $1.0 \mathrm{~mm}$. For 3D FLAIR, the following imaging parameters were used: $5,000 / 333 / 1800 / 1 / 235 / 248 \times 256 / 24 \mathrm{~cm} / 1.0 \mathrm{~mm} / 2 / 5 \mathrm{~min}$ and $17 \mathrm{~s}$ (repetition time ms/echo time $\mathrm{ms} /$ inversion time/ NEX/echo train length/matrix/field of view/section thickness/ reduction factor/imaging time, respectively).

\section{Image interpretation}

\section{- Quantitative assessments}

According to the previous method[12,13], quantitative MRI evaluations were performed by one radiologist (** with 5 years of experience in neuroradiology).

In the current study, on the coronal and sagittal FLAIR images, the radiologist measured the z-Evans Index, an alternative to the Evans Index. Previous investigators found that, by using quantitative volumetric analyses, the volume expansion of the bilateral ventricles, especially at the frontal horns, was toward the z-axial direction, rather than the x-axial direction, in patients with NPH. They therefore newly proposed the z-Evans Index, which was a representative index for z-axial directional expansion of the frontal horns of the bilateral ventricles[12]. The "z-Evans Index" was defined as the maximum z-axial length of the frontal horns to the maximum cranial z-axial length (Fig. 1A). The radiologist also used FLAIR images to measure the callosal angle (Fig. 1B), which is the angle between the lateral ventricles on a coronal image through the posterior commissure, perpendicular to the anterior/posterior commissure plane[13].

- Qualitative assessments

Two certified neuroradiologists (** and ** with 12 and 24 years of experience in neuroradiology, respectively) who did not take part in the image processing independently reviewed the MRI scans and categorized the findings (Sylvian fissure dilation, high-convexity tightness, CS-EPVS, temporo-polar WML, and brain atrophy) by consensus.

The width of the Sylvian fissure was assessed on transverse and coronal sections. We used the following visual rating scale: 1 , narrowed or normal; 2 , mildly dilated; and 3 , severely dilated on the axial and coronal images[14] (Fig. 2). We evaluated the high-convexity tightness on the four uppermost contiguous transverse sections and three contiguous coronal sections on and anterior to the posterior commissure. The severity of the high-convexity tightness was visually rated as follows: 1 , dilated or normal; 2 , mildly tight (tightness was observed over less than three-quarters of the high-convexity space); and 3, extremely tight (tightness was observed over three-quarters or more of the high-convexity space) (Fig. 3). 
According to the previous reports[15], on T2WI, the radiologists assessed the presence of EPVS in the CS (CS-EPVS: identified along the perforating medullary arteries as they penetrated the cortical gray matter over the high convexities and extended into the white matter). The CS-EPVS were coded with the following scale (which was applied to standard axial images): $0=$ no EPVS, $1=1$ to 10 EPVS, $2=11$ to 20 EPVS, $3=21$ to 40 EPVS, and $4=>40$ EPVS). The radiologists also evaluated the 3D FLAIR images for the presence or absence of temporo-polar WMLs. Brain atrophy was defined as enlargement of the gyri and rated on a subjective scale of 0 to $3(0=$ absent, $1=$ mild, $2=$ moderate, $3=$ severe $)[16]$.

\section{Statistical analyses}

For the analyses, the age, CTG repeat numbers, z-Evans Index, and callosal angle were treated as continuous variables, while the sex, high convexity tightness, Sylvian fissure dilation, CS-EPVS, and temporo-polar WMLs were treated as categorical variables.

A z-Evans Index of $>0.3$ was arbitrarily defined as ventriculomegaly. For the subjective scale of highconvexity tightness and Sylvian fissure dilation, the " 2 or 3 " were defined as pathologic findings. Thus, high-convexity tightness (2 or 3 ) combined with Sylvian fissure dilation (2 or 3 ) accompanied by ventriculomegaly was defined as DESH (Fig. 3B). We defined high CS-EPVS (3 or 4) as the presence of > 20 EPVS, in line with the most severe category of EPVS used in previous studies[17,15]. For the subjective scale of brain atrophy, "2 or 3" was defined as pathological brain atrophy.

We compared the clinical and imaging characteristics between patients and controls using Fisher's exact test for categorical variables and the Mann-Whitney U test for continuous variables, as appropriate. To determine the imaging characteristics (callosal angle, Sylvian fissure dilation, high-convexity tightness, CS-EPVS, temporo-polar WML, and pathological brain atrophy) and the patient age that were associated with the z-Evans Index, we conducted multivariate logistic regression analyses. Multivariate analyses were performed by excluding the finding of "high-convexity tightness" because the "high-convexity tightness" and "Sylvian fissure dilation" are obvious confounding factors. We divided the DM1 patients into three age groups: $\leq 39,40-49$, and $\geq 50$ years old (Groups A, B, and C, respectively). We compared the clinical and imaging characteristics among the three age groups using the Steel-Dwass test for continuous variables and Ryan's procedure for categorical variables. All analyses, $P$ values $<0.05$ were considered indicate statistical significance. All of the statistical analyses were performed using the $R$ software program [18].

\section{Results}

Table 1 summarizes the clinical and radiological characteristics of the DM1 patients and controls. The zEvans Index was significantly larger in the patients than in the controls $(0.30 \pm 0.05$ vs. $0.24 \pm 0.02 ; p<$ 0.01 ). The Sylvian fissure dilation ( $54 \%$ vs. $4 \%$; $<<0.01$ ), temporo-polar WML ( $73 \%$ vs. $0 \% ; p<0.01)$, and pathological brain atrophy $(41 \%$ vs. $2 \%$; $<<0.01)$ were more commonly seen in the patients than in the controls. 
Table 2 lists the results of the multivariate logistic analyses for the z-Evans Index. The z-Evans Index was independently associated with the patient age $(p<0.05)$, the callosal angle $(p<0.01)$, Sylvian fissure dilation $(p<0.01)$, and pathological brain atrophy $(p<0.01)$ but not with CTG repeat numbers, CS-EPVS, or temporo-polar WML.

Table 2

The multivariable linear regression analyses for the Z-Evans Index in DM1 patients

\begin{tabular}{|c|c|c|c|}
\hline & & \multicolumn{2}{|c|}{ multivariable linear regression analyses } \\
\hline & & $\begin{array}{l}\text { standardized partial regression } \\
\text { coefficient }\end{array}$ & $\begin{array}{l}\mathrm{p} \\
\text { value }\end{array}$ \\
\hline $\begin{array}{l}\text { Clinical } \\
\text { characteristics }\end{array}$ & age & 0.160 & $<.05$ \\
\hline DM1 related factors & CTG repeat numbers & -0.064 & 0.38 \\
\hline \multirow{5}{*}{$\begin{array}{l}\text { Imaging } \\
\text { characteristics }\end{array}$} & callosal angle & -0.467 & $<.01$ \\
\hline & Sylvian fissure dilation & 0.217 & $<.01$ \\
\hline & CS-EPVS & -0.088 & 0.24 \\
\hline & temporo-polar WML & 0.108 & 0.14 \\
\hline & $\begin{array}{l}\text { pathological brain } \\
\text { atrophy }\end{array}$ & 0.242 & $<.01$ \\
\hline $\begin{array}{l}\text { Abbreviations: DM1 = } \\
\text { semiovale; temporo-p }\end{array}$ & $\begin{array}{l}\text { yotonic dystrophy type } 1 ; \\
\text { I WML = temporo-polar } \mathrm{W}\end{array}$ & $\begin{array}{l}\text { EPVS = enlarged perivascular s } \\
\text { e matter lesion. }\end{array}$ & entrum \\
\hline
\end{tabular}

Figure 4 shows the proportion of imaging features for each age group of DM1 patients. As shown in Group C in Fig. 4, ventriculomegaly was observed in $21(61.8 \%)$ of 34 patients. Most $(n=18)$ of the 21 patients with ventriculomegaly in Group C showed Sylvian fissure dilation, whereas only 5 of the 11 patients with ventriculomegaly in Group A showed it. In Group C, high-convexity tightness was found in 7 patients (20.6\%), all of whom had ventriculomegaly as well as Sylvian fissure dilation and were thus diagnosed with DESH. No and two patients were diagnosed with DESH in Groups A and B, respectively.

Table 3 summarizes the clinical and imaging characteristics for the age group comparisons in DM1 patients. The z-Evans Index was significantly higher in Group $C$ than in Groups $A(p<0.01)$ or $B(p<0.05)$. The presence of the DESH was more commonly seen in Group $C$ than in Group $A(p<0.01)$. With regard to the other imaging characteristics (callosal angle, CS-EPVS, temporo-polar WMLs, and pathological brain atrophy), there were no statistically significant differences among the three age groups. 
Table 3

Findings according to the age of DM1 patients

\begin{tabular}{|c|c|c|c|c|c|c|c|}
\hline & & $\begin{array}{l}\text { Group A } \\
\leq \\
39 \text { years } \\
\text { old } \\
(n=36)\end{array}$ & $\begin{array}{l}\text { Group B } \\
40- \\
49 \text { years } \\
\text { old } \\
(n=42)\end{array}$ & $\begin{array}{l}\text { Group C } \\
\geq \\
50 \text { years } \\
\text { old } \\
(n=34)\end{array}$ & $\begin{array}{l}\text { Group } \\
\text { A vs B }\end{array}$ & $\begin{array}{l}\text { Group } \\
\text { A vs C }\end{array}$ & $\begin{array}{l}\text { Group } \\
\text { B vs C }\end{array}$ \\
\hline \multirow[t]{2}{*}{$\begin{array}{l}\text { Clinical } \\
\text { characteristics }\end{array}$} & Age, mean (IQR) & $\begin{array}{l}33.5 \\
(29.5- \\
36)\end{array}$ & $\begin{array}{l}45 \\
(42-47)\end{array}$ & $\begin{array}{l}55.5 \\
(53-61)\end{array}$ & NA & NA & NA \\
\hline & sex, female (\%) & $16(44)$ & $15(36)$ & $17(50)$ & NS & NS & NS \\
\hline $\begin{array}{l}\text { DM related } \\
\text { factors }\end{array}$ & $\begin{array}{l}\text { CTG repeat } \\
\text { numbers, mean } \\
\text { (IQR) }\end{array}$ & $\begin{array}{l}1100 \\
(600- \\
1450)\end{array}$ & $\begin{array}{l}950 \\
(700- \\
1200)\end{array}$ & $\begin{array}{l}833 \\
(550- \\
1200)\end{array}$ & NS & NS & NS \\
\hline \multirow[t]{6}{*}{$\begin{array}{l}\text { Imaging } \\
\text { characteristics }\end{array}$} & Z-El, mean (IQR) & $\begin{array}{l}0.282 \\
(0.250- \\
0.303)\end{array}$ & $\begin{array}{l}0.291 \\
(0.278- \\
0.313)\end{array}$ & $\begin{array}{l}0.313 \\
(0.283- \\
0.374)\end{array}$ & NS & * & ** \\
\hline & $\begin{array}{l}\text { callosal angle, } \\
\text { mean (IQR) }\end{array}$ & $\begin{array}{l}123 \\
(119- \\
129)\end{array}$ & $\begin{array}{l}123 \\
(112- \\
129)\end{array}$ & $\begin{array}{l}125 \\
(103- \\
129)\end{array}$ & NS & NS & NS \\
\hline & DESH, n (\%) & $0(0)$ & $2(5)$ & $7(21)$ & NS & * & NS \\
\hline & CS-EPVS, n (\%) & $17(47)$ & $10(24)$ & $8(24)$ & NS & NS & NS \\
\hline & $\begin{array}{l}\text { temporo-polar } \\
\text { WML, n (\%) }\end{array}$ & $25(69)$ & $30(71)$ & $27(79)$ & NS & NS & NS \\
\hline & $\begin{array}{l}\text { pathological brain } \\
\text { atrophy, n (\%) }\end{array}$ & $13(36)$ & $21(50)$ & $12(35)$ & NS & NS & NS \\
\hline \multicolumn{8}{|c|}{$\begin{array}{l}\text { Abbreviations: DM1 = myotonic dystrophy type 1; IQR = interquartile range; NA = not applicable; } N S= \\
\text { not significant; } Z \text {-EI, = Z-Evans Index; DESH = disproportionately enlarged subarachnoid space } \\
\text { hydrocephalus; CS-EPVS = enlarged perivascular spaces in centrum semiovale; temporo-polar WML = } \\
\text { temporo-polar white matter lesion. }\end{array}$} \\
\hline
\end{tabular}

\section{Discussion}

In the present study, we evaluated DM1 patients using the newly proposed z-Evans Index. Although the original Evans Index has been adopted as a criterion for discriminating the tap-test response[19], the zEvans Index has been shown to have a higher diagnostic accuracy[12]. We found that the z-Evans Index of DM1 was significantly higher than that of control patients. Furthermore, the z-Evans Index was 
significantly associated with the patients' age. These results were consistent with those of previous studies showing that cerebral ventriculomegaly was common in DM1 patients and appeared to be progressive[9].

It is important to note that an increased z-Evans Index (ventriculomegaly) was independently associated with the callosal angle and Sylvian fissure dilation. The callosal angle is an imaging biomarker of NPH[9]. A previous NPH study showed that a small callosal angle on preoperative MRI was a significant predictor of a positive shunt outcome[13]. Another study showed a significantly decreased mean callosal angle in patients with NPH $(109 \pm 9)$ compared with patients with Alzheimer's disease (AD) $(135.4 \pm 11.3)$ or dementia with Lewy bodies (DLB) $(136.9 \pm 8.2)$ [20]. The mean callosal angle $\left(113 \pm 26.4^{\circ}\right)$ in our elderly patients (Group C) (Table 3), which might be close to that in NPH, was smaller than that reported in AD and DLB cases[20]. These results suggest that the morphologic changes accompanied by ventriculomegaly in DM1 patients are similar to those in patients with NPH. Furthermore, we found that DESH was observed in $20.6 \%$ of elderly patients with DM1 in our study. Previously, five cases with NPH in association with DM1 have been reported[10]. Three of those five patients received shunt surgery, and their condition markedly improved. These cases may support our results, as all of the cases were more than 50 years old, suggesting that DM1 patients may develop an NPH pathology later in life. Although cognitive deficits were found in a high percentage of DM1 patients at a late stage[6,21,22], the exact mechanism remains unclear. Therefore, further prospective studies with a larger number of DM1 patients are needed to determine whether or not an NPH-like appearance is associated with neuropsychological deficits.

The mechanism underlying the manifestation of NPH may be the obliteration of arachnoid villi (small protrusions of the arachnoid mater that return the cerebrospinal fluid [CSF] to the venous circulation), leading to disrupted CSF reabsorption and subsequent ventriculomegaly[23,24]. However, the etiology and pathophysiology of the NPH-like appearance in DM1 are uncertain. One possible mechanism suspected by previous investigators involves widespread cell membrane defects caused by genetic abnormalities in DM1[10,25], leading to arachnoid granulations[26]. Another possible mechanism may be glymphatic system dysfunction in DM1. The glymphatic system is an effective waste clearance pathway that removes metabolic wastes and neurotoxins from the brain along paravascular channels[27]. The anatomical pathways for the glymphatic system are the perivascular spaces. While the perivascular spaces terminate within the brain parenchyma, paravascular CSF can continue traveling along the basement membranes surrounding arterial vascular smooth muscle[28]. In a previous neuropathological study, DM1 brain showed EPVS in the basal forebrain and deep white matter along with a loss of smooth muscles in small to medium-sized arteries[29]. A previous MRI study also showed that EPVS were significantly more frequent in DM1 patients (67\%) than in controls (27\%)[7]. Ringstad et al. demonstrated the reduced glymphatic clearance in idiopathic NPH using glymphatic MRI and hypothesized that a reduced glymphatic function is instrumental for dementia in NPH[30]. Based on these previous findings, we suspect that the EPVS and NPH-like appearance in DM1 might reflect a pathology of glymphatic system dysfunction. 
Costanzo et al. showed a significant negative correlation between the degree of EPVS and disease duration and suggested that EPVS might progressively disappear during the disease course[7]. Our results regarding the patient age also showed that the presence of CS-EPVS was more common in Group A than in Groups B and C, although there were no significant differences. Furthermore, regarding the frequency of temporo-polar WMLs, we found no significant differences among the age groups. These results suggest that CS-EPVS and/or temporo-polar WMLs may be findings at the early stage of DM1. Most of the elderly patients (Group C) with ventriculomegaly showed Sylvian fissure dilation, whereas only half of the younger patients showed this finding (Group A). In addition, we found that all patients with high-convexity tightness had ventriculomegaly as well as Sylvian fissure dilation. These results suggest that ventriculomegaly might precede the development of Sylvian fissure dilation and highconvexity tightness in DM1.

In DM1, the classic disease range of CTG repeat numbers is $50-4000$, with repeat sizes of $50-80$ associated with mild clinical phenotypes, while large repeat expansions of up to 4000 are often found in severe, mostly congenital forms of the disorder[31]. Brain abnormalities, including issues with cognitive function and muscle weakness, have been linked to the CTG repeat numbers, cognitive function, and muscle weaknes[32,31,33]. However, the present study showed no correlation between the z-Evans Index and the CTG repeat numbers. Although the reason for this finding remains unclear, one possible reason is the small sample size of elderly patients with large repeat expansions because of their poor prognosis. Furthermore, our negative result may be supported by the findings of previous studies; for example, Minnerop et al. noted no correlations between neuropsychological test results and CTG repeat numbers[31]. With regard to neuroimaging assessments, temporo-polar WMLs have shown no correlation with CTG repeat numbers[7].

This study was limited by its retrospective design. Thus, neuropsychological tests were not performed in many cases, as neuropsychological deficits in cases of myotonic dystrophy can escape commonly applied neuropsychological test batteries for as-yet-unclear reasons. Moreover, no patients undergo lumbar puncture and were clinically diagnosed as having NPH. Second, all subjects were examined by 1.5-T MRI rather than 3-T MRI. However, we believe that the image quality with our MRI protocols was sufficient for the evaluation of the proposed method. We arbitrarily defined ventriculomegaly as a z-Evans index of $>0.3$ because an NPH-like appearance in DM1 patients is a relatively new finding.

\section{Conclusions}

Our MRI study revealed an NPH-like appearance as a morphologic finding accompanied by ventriculomegaly in DM1 that tends to occur in elderly patients. Furthermore, because cognitive deficits are found in a high percentage of DM1 patients at the late stage, correlation analyses between neuropsychological deficits and the NPH-like appearances might be an interesting topic for a further study involving more patients.

\section{Abbreviations}


$\mathrm{DM} 1=$ myotonic dystrophy type 1

$\mathrm{NPH}=$ normal pressure hydrocephalus

DESH = disproportionately enlarged subarachnoid-space hydrocephalus

EPVS $=$ enlarged perivascular spaces

$\mathrm{CS}=$ centrum semiovale

\section{Declarations}

\section{Ethics approval and consent to participate:}

All procedures performed in the studies involving human participants were in accordance with the ethical standards of the institutional and/or national research committee and with the 1964 Helsinki Declaration and its later amendments or comparable ethical standards. Our study was approved by the institutional review board, which waived informed consent because it was retrospective.

\section{Consent to publish:}

All authors consent to publish.

\section{Availability of data and materials:}

The datasets during and/or analysed during the current study available from the corresponding author on reasonable request.

\section{Competing interests:}

All authors declare that they have no conflict of interest.

\section{Funding:}

In all authors, no funding was received for this study.

\section{Authors' Contributions:}

- Conceptualization: Saya lida, Shingo Kakeda

- Data curation: Saya lida, Hiroko Seino, Shingo Kakeda

- Formal Analysis: Saya lida

- Funding acquisition: Seiko Kon, Hiroto Takada

- Investigation: Seiko Kon, Hiroto Takada Sho Maruyama, Soichiro Tatsuo, Hiroko Seino, Fumiko Nagahata, Fumiyasu Tsushima 
- Methodology: Hiroko Seino, Shingo Kakeda, Masashi Matsuzaka, Koichiro Sugimoto

- Project administration: Hiroko Seino, Shingo Kakeda

- Resources: Seiko Kon, Hiroto Takada

- Supervision: Hiroto Takada, Shingo Kakeda

- Validation: Seiko Kon, Hiroto Takada

- Visualization: Saya lida, Hiroko Seino, Fumiko Nagahata

- Writing - original draft: Saya lida

- Writing - review \& editing: Shingo Kakeda

\section{Acknowledgements:}

Not applicable

\section{References}

1. Udd B, Krahe R (2012) The myotonic dystrophies: molecular, clinical, and therapeutic challenges. The Lancet Neurology 11 (10):891-905

2. nomenclature N, 1 Dtgfmdt (2000) The International Myotonic Dystrophy Consortium (IDMC). Neurology 54:1218-1221

3. Consortium IMD (2000) New nomenclature and DNA testing guidelines for myotonic dystrophy type 1 (DM1). Neurology 54 (6):1218-1221

4. Di Costanzo A, Di Salle F, Santoro L, Bonavita V, Tedeschi G (2001) T2 relaxometry of brain in myotonic dystrophy. Neuroradiology 43 (3):198-204

5. Miaux Y, Chiras J, Eymard B, Lauriot-Prevost M, Radvanyi H, Martin-Duverneuil N, Delaporte C (1997) Cranial MRI findings in myotonic dystrophy. Neuroradiology 39 (3):166-170

6. Huber SJ, Kissel JT, Shuttleworth EC, Chakeres DW, Clapp LE, Brogan MA (1989) Magnetic resonance imaging and clinical correlates of intellectual impairment in myotonic dystrophy. Archives of neurology 46 (5):536-540

7. Di Costanzo A, Di Salle F, Santoro L, Tessitore A, Bonavita V, Tedeschi G (2002) Pattern and significance of white matter abnormalities in myotonic dystrophy type 1: an MRI study. Journal of neurology 249 (9):1175-1182

8. Hashimoto M, Ishikawa M, Mori E, Kuwana N, Improvement SoloN (2010) Diagnosis of idiopathic normal pressure hydrocephalus is supported by MRI-based scheme: a prospective cohort study. Cerebrospinal fluid research 7 (1):18

9. Di Costanzo A, Di Salle F, Santoro L, Bonavita V, Tedeschi G (2002) Brain MRI features of congenitaland adult-form myotonic dystrophy type 1: case-control study. Neuromuscular Disorders 12 (5):476483 
10. Wang J, Liu M, Shang W, Chen Z, Peng G (2020) Myotonic dystrophy type 1 accompanied with normal pressure hydrocephalus: a case report and literature review. BMC neurology 20 (1):1-6

11. Brook JD, McCurrach ME, Harley HG, Buckler AJ, Church D, Aburatani H, Hunter K, Stanton VP, Thirion J-P, Hudson T (1992) Molecular basis of myotonic dystrophy: expansion of a trinucleotide (CTG) repeat at the $3^{\prime}$ end of a transcript encoding a protein kinase family member. Cell 68 (4):799-808

12. Yamada S, Ishikawa M, Yamamoto K (2015) Optimal diagnostic indices for idiopathic normal pressure hydrocephalus based on the 3D quantitative volumetric analysis for the cerebral ventricle and subarachnoid space. American Journal of Neuroradiology 36 (12):2262-2269

13. Virhammar J, Laurell K, Cesarini KG, Larsson E-M (2014) Preoperative prognostic value of MRI findings in 108 patients with idiopathic normal pressure hydrocephalus. American Journal of Neuroradiology 35 (12):2311-2318

14. Narita W, Nishio Y, Baba T, lizuka O, Ishihara T, Matsuda M, Iwasaki M, Tominaga T, Mori E (2016) High-convexity tightness predicts the shunt response in idiopathic normal pressure hydrocephalus. American Journal of Neuroradiology 37 (10):1831-1837

15. Miyata M, Kakeda S, Iwata S, Nakayamada S, Ide S, Watanabe K, Moriya J, Tanaka Y, Korogi Y (2017) Enlarged perivascular spaces are associated with the disease activity in systemic lupus erythematosus. Scientific reports 7 (1):1-10

16. Farrell C, Chappell F, Armitage P, Keston P, MacLullich A, Shenkin S, Wardlaw J (2009) Development and initial testing of normal reference MR images for the brain at ages 65-70 and 75-80 years. European radiology $19(1): 177-183$

17. Charidimou A, Jaunmuktane Z, Baron J-C, Burnell M, Varlet P, Peeters A, Xuereb J, Jäger R, Brandner S, Werring DJ (2014) White matter perivascular spaces: an MRI marker in pathology-proven cerebral amyloid angiopathy? Neurology $82(1): 57-62$

18. Team RC (2014) R: A language and environment for statistical computing. R Foundation for Statistical Computing, Vienna, Austria. 2013. ISBN 3-900051-07-0,

19. EVANS WA (1942) An encephalographic ratio for estimating ventricular enlargement and cerebral atrophy. Archives of Neurology \& Psychiatry 47 (6):931-937

20. Cagnin A, Simioni M, Tagliapietra M, Citton V, Pompanin S, Della Puppa A, Ermani M, Manara R (2015) A simplified callosal angle measure best differentiates idiopathic-normal pressure hydrocephalus from neurodegenerative dementia. Journal of Alzheimer's Disease 46 (4):1033-1038

21. Meola G, Sansone V, Perani D, Colleluori A, Cappa S, Cotelli M, Fazio F, Thornton C, Moxley R (1999) Reduced cerebral blood flow and impaired visual-spatial function in proximal myotonic myopathy. Neurology 53 (5):1042-1042

22. Modoni A, Silvestri G, Pomponi MG, Mangiola F, Tonali PA, Marra C (2004) Characterization of the pattern of cognitive impairment in myotonic dystrophy type 1. Archives of neurology 61 (12):19431947

23. Raftopoulos C, Chaskis C, Delecluse F, Cantrainet F, Bidauti L, Brotchi J (1992) Morphological quantitative analysis of intracranial pressure waves in normal pressure hydrocephalus. Neurological 
research 14 (5):389-396

24. Raftopoulos C, Deleval J, Chaskis C, Leonard A, Cantraine F, Desmyttere F, Clarysse S, Brotchi J (1994) Cognitive recovery in idiopathic normal pressure hydrocephalus: a prospective study. Neurosurgery 35 (3):397-405

25. Christensen PB (1988) Normal pressure hydrocephalus in myotonic dystrophy. European neurology 28 (5):285-287

26. Duinkerke A, Williams MA, Rigamonti D, Hillis AE (2004) Cognitive recovery in idiopathic normal pressure hydrocephalus after shunt. Cognitive and behavioral neurology 17 (3):179-184

27. Jessen NA, Munk ASF, Lundgaard I, Nedergaard M (2015) The glymphatic system: a beginner's guide. Neurochemical research 40 (12):2583-2599

28. Rennels ML, Gregory TF, Blaumanis OR, Fujimoto K, Grady PA (1985) Evidence for a 'paravascular'fluid circulation in the mammalian central nervous system, provided by the rapid distribution of tracer protein throughout the brain from the subarachnoid space. Brain research 326 (1):47-63

29. Itoh K, Mitani M, Kawamoto K, Futamura N, Funakawa I, Jinnai K, Fushiki S (2010) Neuropathology does not correlate with regional differences in the extent of expansion of CTG repeats in the brain with myotonic dystrophy type 1. Acta histochemica et cytochemica:1012160093-1012160093

30. Ringstad G, Vatnehol SAS, Eide PK (2017) Glymphatic MRI in idiopathic normal pressure hydrocephalus. Brain 140 (10):2691-2705

31. Minnerop M, Weber B, Schoene-Bake J-C, Roeske S, Mirbach S, Anspach C, Schneider-Gold C, Betz RC, Helmstaedter C, Tittgemeyer M (2011) The brain in myotonic dystrophy 1 and 2: evidence for a predominant white matter disease. Brain 134 (12):3530-3546

32. Antonini G, Mainero C, Romano A, Giubilei F, Ceschin V, Gragnani F, Morino S, Fiorelli M, Soscia F, Di Pasquale A (2004) Cerebral atrophy in myotonic dystrophy: a voxel based morphometric study. Journal of Neurology, Neurosurgery \& Psychiatry 75 (11):1611-1613

33. Weber YG, Roebling R, Kassubek J, Hoffmann S, Rosenbohm A, Wolf M, Steinbach P, Jurkat-Rott K, Walter H, Reske SN (2010) Comparative analysis of brain structure, metabolism, and cognition in myotonic dystrophy 1 and 2. Neurology 74 (14):1108-1117

\section{Figures}




\section{Figure 1.}
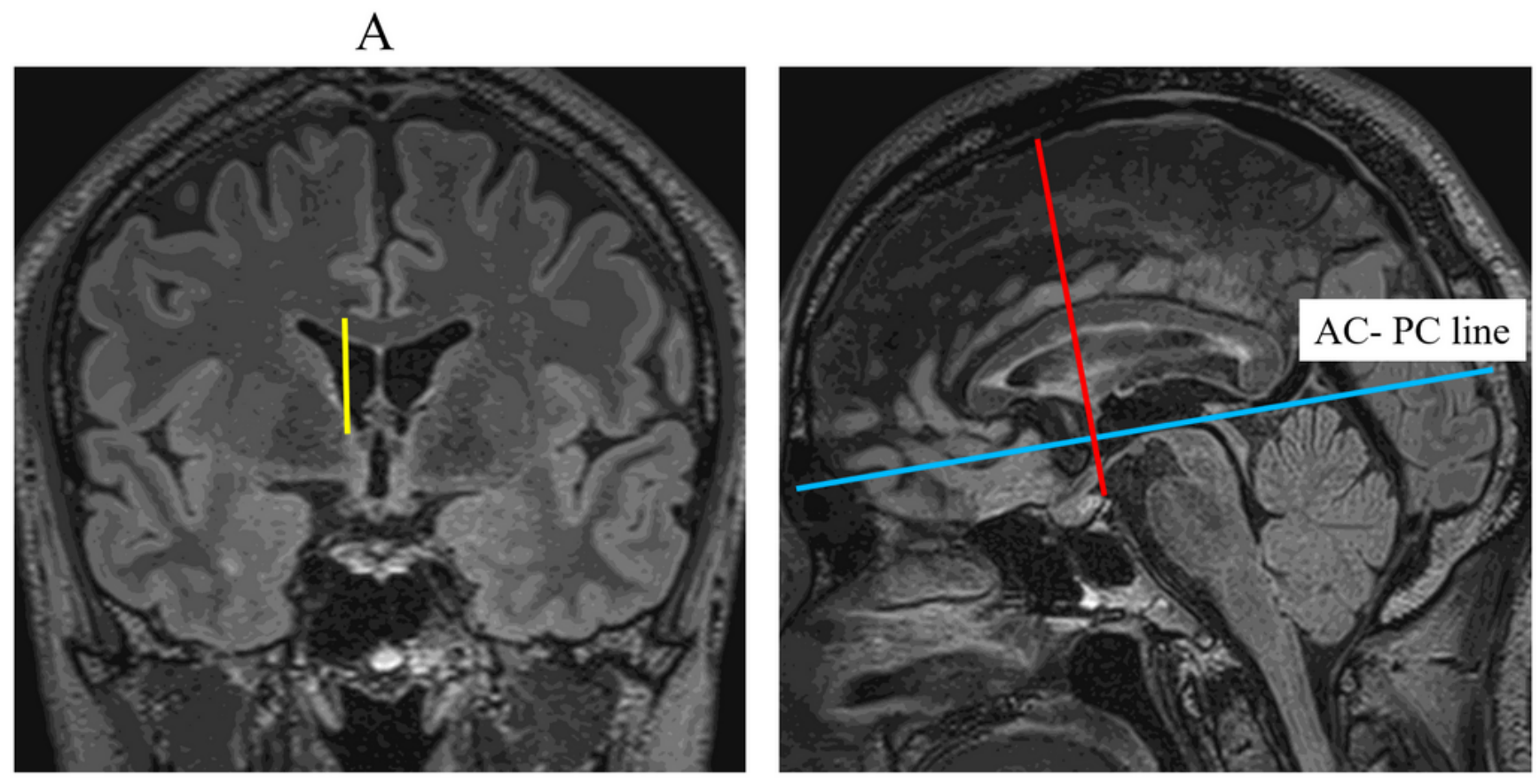

B

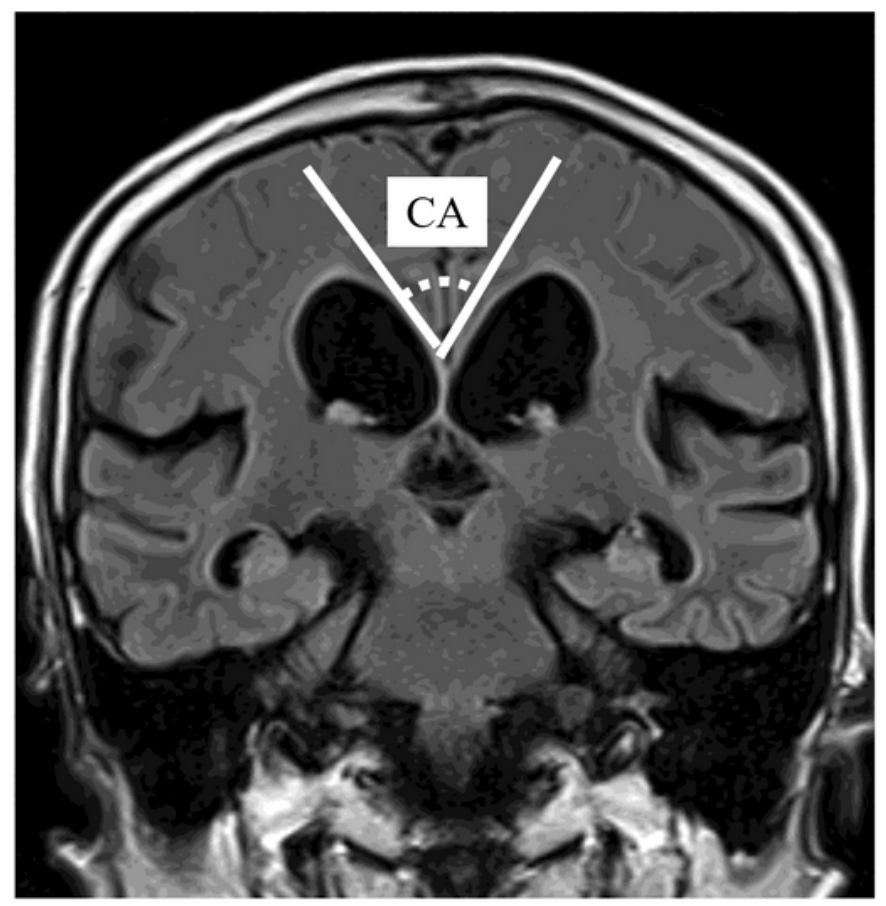

Figure 1

A. z-Evans Index. The figures are the MPR reconstructions of 3D FLAIR images. The z-Evans Index is defined as the maximum length from the foramen of Monro to the superior margin of the frontal horns (yellow lines) on coronal FLAIR images / the maximum cranial z-axial length (red lines) on sagittal FLAIR images. The blue line indicates the anterior and posterior commissure (AC- PC) line. B. Callosal angle. 
Figure 2.

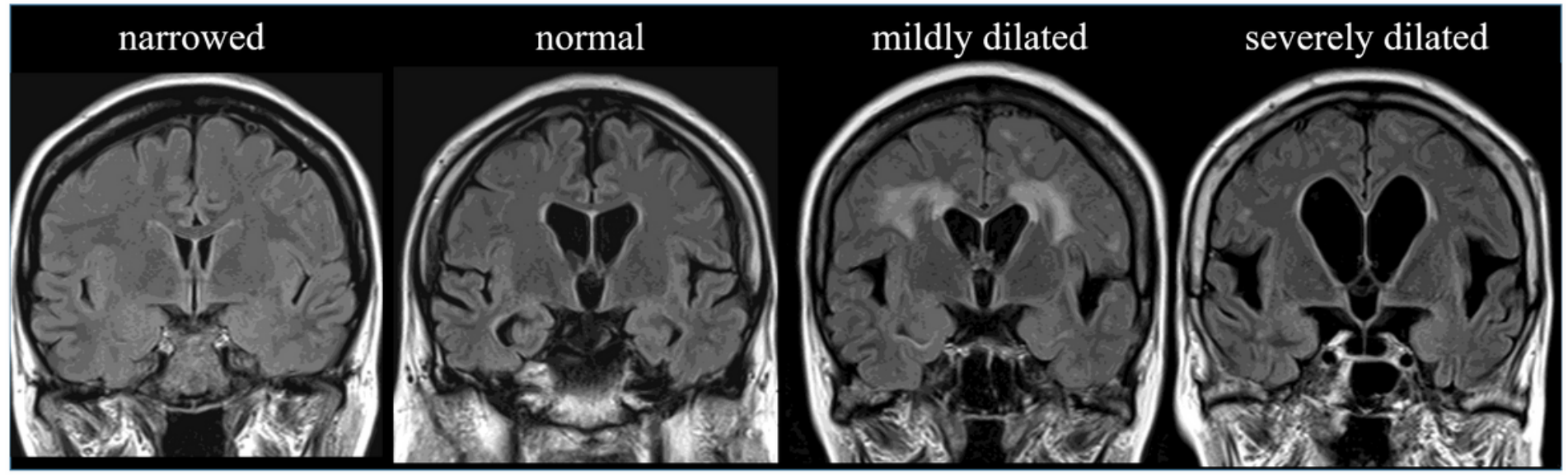

Figure 2

Sylvian fissure dilation. Visual rating scales for Sylvian fissure dilation coronal FLAIR images: 1, narrowed or normal; 2 , mildly dilated; and 3 , severely dilated.

Figure 3.
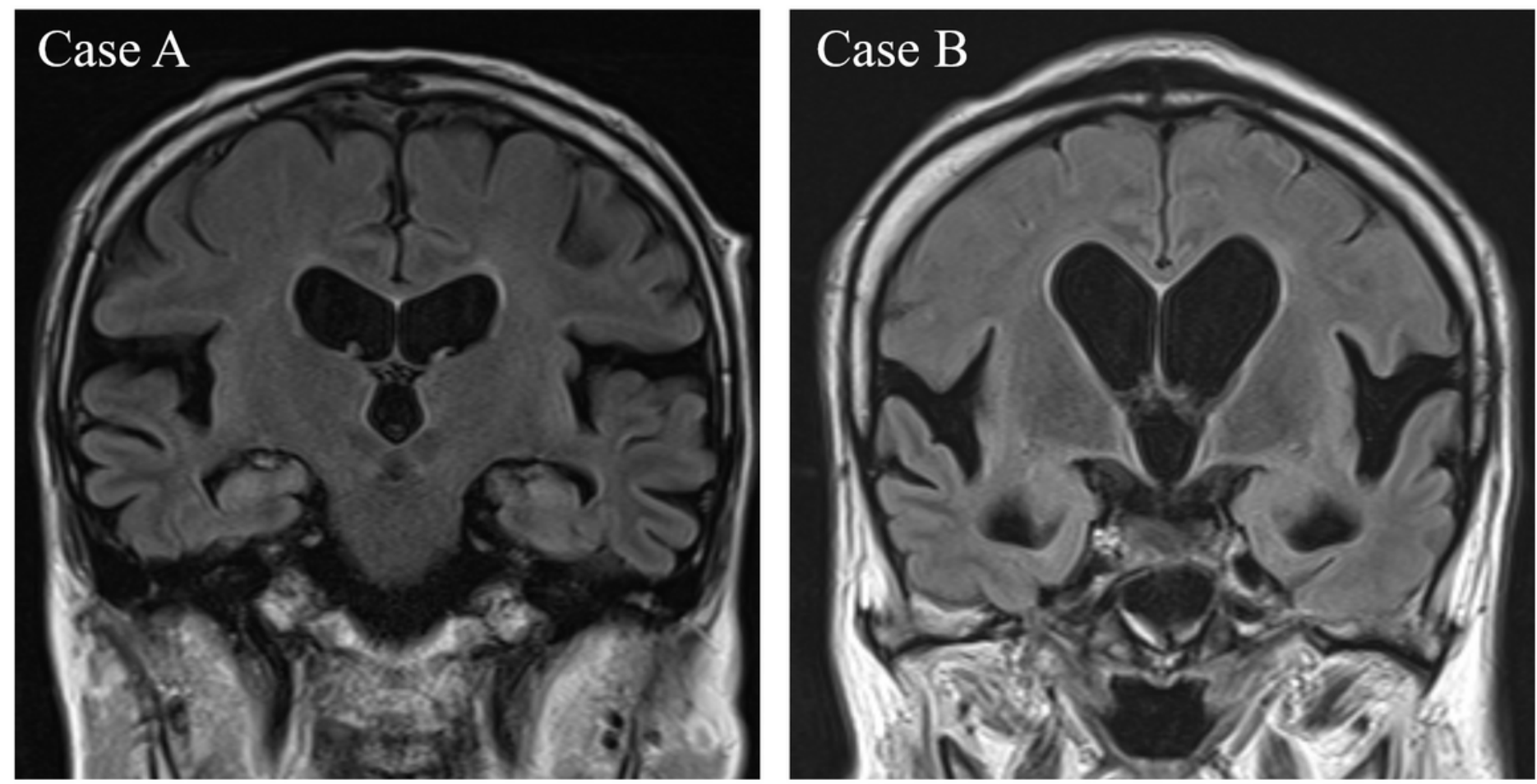

\section{Figure 3}

Case A is rated as "normal" for absence of the high-convexity tightness and "severely dilated" for the Sylvian fissure dilation. Case B is rated as "extremely tight" for the high-convexity tightness and "severely 
dilated" for the Sylvian fissure dilation. Therefore, Case B shows the findings of disproportionately enlarged subarachnoid space hydrocephalus (DESH).

Figure 4.

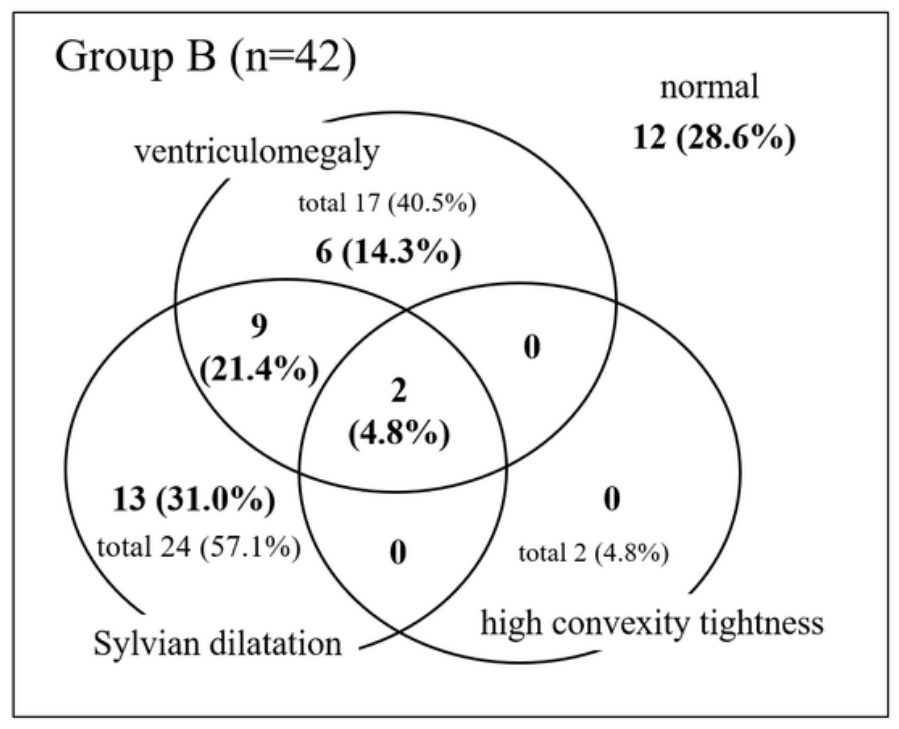

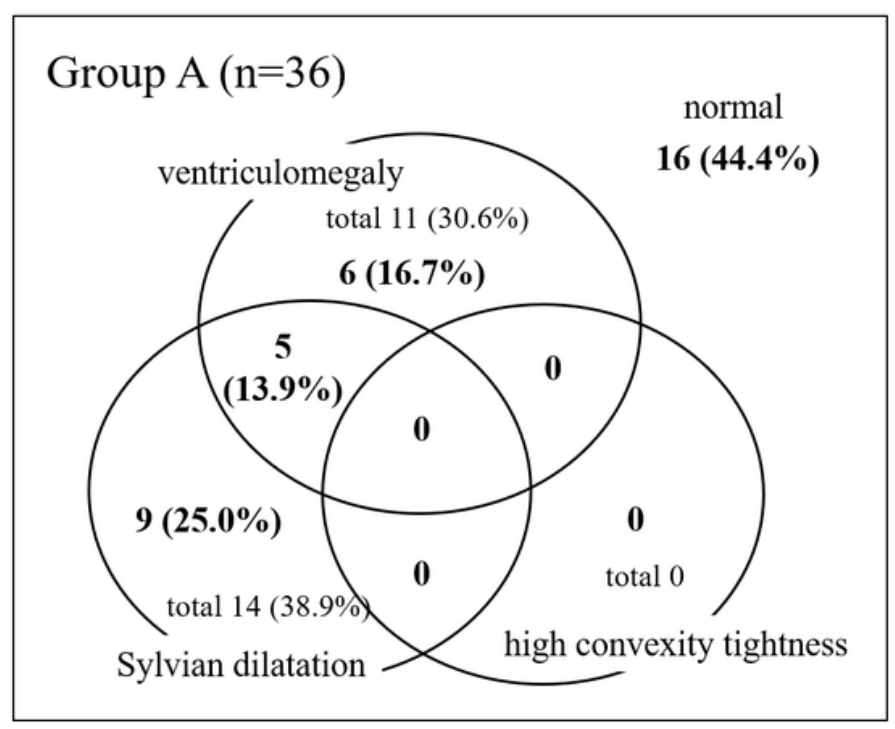

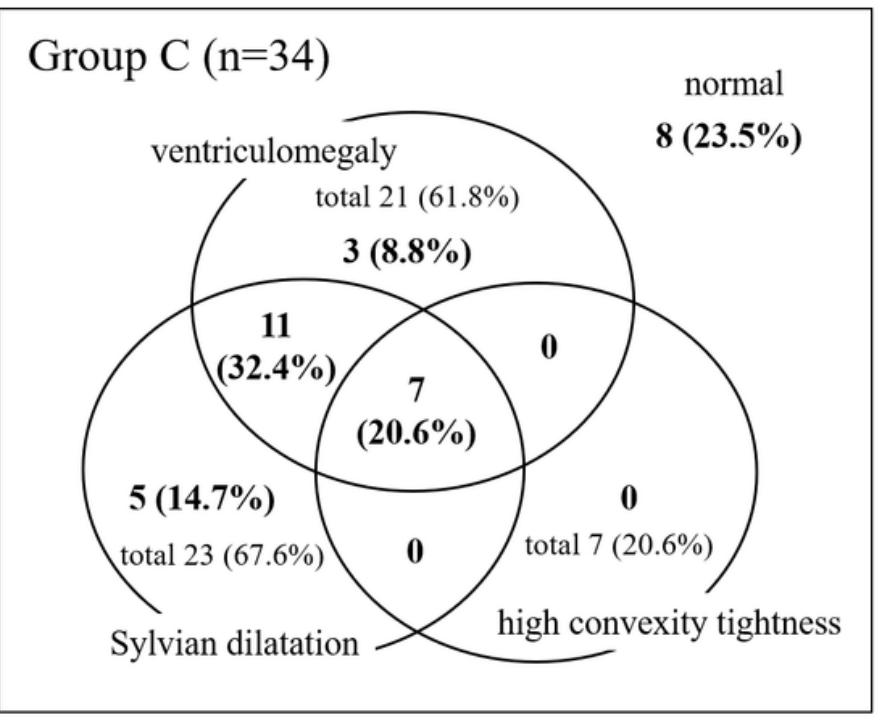

\section{Figure 4}

The proportion of imaging features for each age group of DM1 patients. Group A: $\leq 39$ years old. Group B: $40-49$ years old. Group C: $\geq 50$ years old. A z-Evans Index of $>0.3$ was defined as ventriculomegaly. For the subjective scale of high-convexity tightness and Sylvian fissure dilation, "2 or 3" was considered a pathologic finding. Thus, high-convexity tightness (2 or 3) combined with Sylvian fissure dilation (2 or 3 ) accompanied by ventriculomegaly was defined as disproportionately enlarged subarachnoid space hydrocephalus (DESH). 